\title{
En busca del tiempo perdido
}

la memoria de la educación

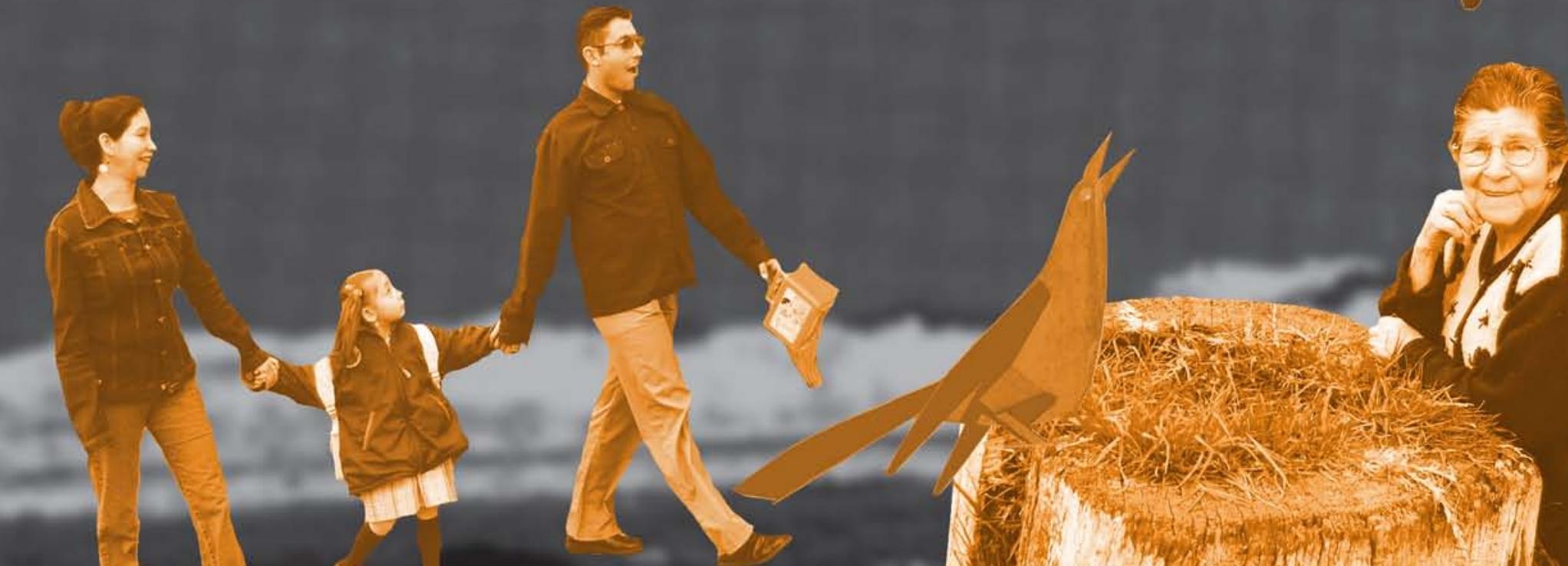




\section{Resumen/Abstract}

En este artículo se describe y analiza la creación del Centro de Memoria de Educación de la Facultad de Educación de la UNICAMP/Brasil -espacio de investigación sobre cuestiones de memoria/historia y educación-, a la vez que refleja las políticas culturales para la memoria y la preservación patrimonial de la educación, las tensiones y posibilidades de su efectividad como centro de investigación y como espacio institucional que contribuye en la formación de educadores. Al mismo tiempo, propone ampliar las discusiones sobre la memoria de la educación, en lo que se refiere a la vinculación de la memoria con disputas sobre las identidades y los derechos sociales, y sobre las molestias provocadas por las políticas y prácticas preservacionistas.

\section{Palabras clave: memoria de la educación, cultura y patrimonio, archivos y centros de documentación, recuerdo, políticas culturales, memoria incómoda \\ Key-words: $\quad$ memory of education; culture and patrimony, archives and documentation centres, regret, cultural policies, inconvenient memory}

\section{Looking for the lost Time \\ The Memory of the education}

In this article on describe and analyse the creation of the Centro de Memória da Educação da Faculdade de Educação da UNICAMP/Brasil (Centre for the Memory of Education of the Education College in the University of Campinas - UNICAMP/Brazil) - a place where questions about memory and history of education are researched - reflecting about cultural policies for memory and patrimonial preservation, about the tensions and possibilities for its fulfiment as a centre of research and as an institutional space which contributes to the formation of educators. In the same time, I try to enlarge the discussions about the memory of education, referring to the link of the questions about the memory with identities and social rights, as well as the annoyance provoked by preservationist policies and practices.

\section{Maria do Carmo Martins}

2000. Doctora en Educación. 1996; Maestría en Educación. 1986: Bachillerato y Licenciatura en Historia. Universidad Estatal de Campiñas, UNICAMP. Campiñas, Brasil. Proyectos de investigación: 2005 a la fecha Memorias de educación escolar: cultura material y organización de archivos escolares, proyecto que se vincula la los objetivos y a las líneas de investigación del Centro de Memoria de Educación (CME) de FE/UNICAMP. 2000. Currículos: historia y temas afines. Proyectos sobre la historia del currículo escolar en Brasil. 2000. 2004. Centro de Memoria de Educación. Proyecto de construcción del Centro de Memoria de Educación de la Facultad de Educación de UNICAMP. www.fe.unicamp.br/serviços/index/html. Además de numeros capítulos de libros, artículos en diversos medios, ha publicado con Martins, M. C. Una historia prescrita y disciplinar de nuestros currículos escolares: iquién legitima los saberes? Bragança Paulista : Editora da Universidade São Francisco, 2002, v.1.274 p.e-mail: carminha@unicamp.br

Traducción de Dora Lilia Marín Díaz

Asesora de la Dirección de la Directora del Instituto para la Investigación Educativa y el Desarrollo Pedagógico IDEP. Coordinadora del proyecto Centro de Memoria en Educación y Pedagogía de Bogotá, hasta julio de 2006. 
A memória é um elemento essencial do que se costuma chamar identidade, individual ou coletiva, cuja busca é uma das atividades fundamentais dos indivíduos e das sociedades de hoje, na febre e na angústia

\section{Lê Goff, Jacques \\ História e memória, 1990}

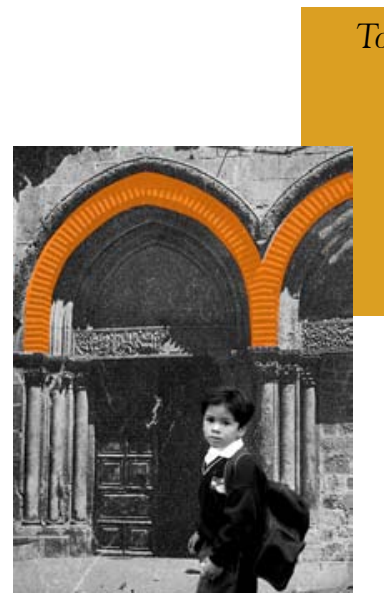

Toda cultura se cria como modelo inerente à duração da própria existência (...), e a continuidade da própria memória. Em tal sentido, todo texto contribui tanto para a memória como para o esquecimento. E um texto não é então a "realidade", mas os materiais para reconstruí-la. A cultura exclui, em continuação, no próprio âmbito, determinados textos, levando em conta todos os tipos de injunção

\section{Ferreira, Jerusa Pire Armadilhas da memória e outros ensaios}

Las palabras de Le Goff y Ferreira me inspiran y me sorprenden. La inspiración es clara: transcurre de la propia manifestación de la positividad de la memoria, puerto seguro para las disputas de la identidad, bálsamo contra el olvido y el pasaje de la propia existencia, lugar donde vemos manifestar y manera más intensa de luchar contra la muerte y contra la mortificación que, algunas veces, nos es impuesta. El asombro, entretanto, insiste en mí, investigadora del tema de la memoria que percibe, incluso de manera desconfiada, un siniestro juego de revitalización de las disputas de la memoria como un bien inexorable, capaz de crear una voluntad política, o tal vez un deseo de superviviencia, que mi experiencia con el mundo no me permite asegurar. Esas sensaciones contradictorias me inspiran reflexiones que pretendo sean colectivas y que apunten a comprender el sentido de la creación del Centro de memoria de educación, de la Facultad de Educación de la Universidad Estatal de Campiñas (CME/FE-UNICAMP), espacio de investigación en memoria, historia y educación que he ayudado a consolidar. El trabajo de organización del Centro y los debates que allí surgen, son materia de este trabajo, el cual recoge comentarios, aclara dudas, plantea incertidumbres, muestra alegrías y satisfacciones, y establece un diálogo franco con las tensiones que el tema y la propuesta suscitan: seducción, trampas olvidos, molestias. 


\section{La seducción}

A muitos os poetas lembrariam que o homem não é para ser engolido por vossas gargantas mentirosas. E sempre um ou dois dos vossos engolidos deixarão suas heranças, suas memórias

A Idéia, meus senhores

E essa é a mais brilhosa do que o brilho fugaz de vossas botas.

Hilda Hilst Poema I, Homenagem aos homens do nosso tempo

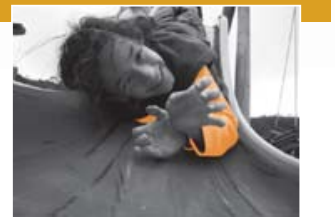

El Centro de memoria de la educación, creado en el 2001 y aún en fase de organización, fue concebido para vincular a Brasil a los debates sobre los modos de abordar la historia de la educación, y plantear preguntas relativas a la historia de las instituciones escolares, culturas de la escuela, educación en espacios no escolares, historia del currículo, formación de profesores, memorias de la escolarización y procesos educativos en los sujetos de la educación, así como realizar investigaciones para definir lo que sería el patrimonio histórico y cultural de la educación. Para esos temas, llama la atención, aún hoy, el hecho de que los investigadores tengan que definir sus fuentes documentales construyendo un acervo; es decir, recuperando documentos dispersos, buscando incesantemente en expediciones y saliendo a múltiples lugares a fin de reconocerlos, produciendo inventarios de fuentes y no raras veces reuniendo, de manera espontánea, fuentes originales (y copiadas) en su propia casa. Por ello, en sus inicios el proyecto tuvo una fuerte inspiración en las discusiones sobre archivos y centros de documentación ${ }^{1}$.

1 Sobre la creación detallada del CME y las dificultades iniciales de su creación, inseridas en el debate de la Facultad de educación, sugiero la lectura del texto en el sector de publicaciones de la página virtual del Centro: CME/FE: www.fe.unicamp.br/serviços/index.html, denominado de Historia do Centro de Memoria. 
Esos espacios de información especializada son fundamentales para el apoyo a la investigación, y en el caso de la Facultad de Educación, se realizaron innumerables intentos de articular investigación y enseñanza en los niveles de pregrado y de posgrado. La creación del Centro consideró la historia de esa institución marcando, desde el inicio, la inserción de actividades a ser realizadas en el CME orientadas a

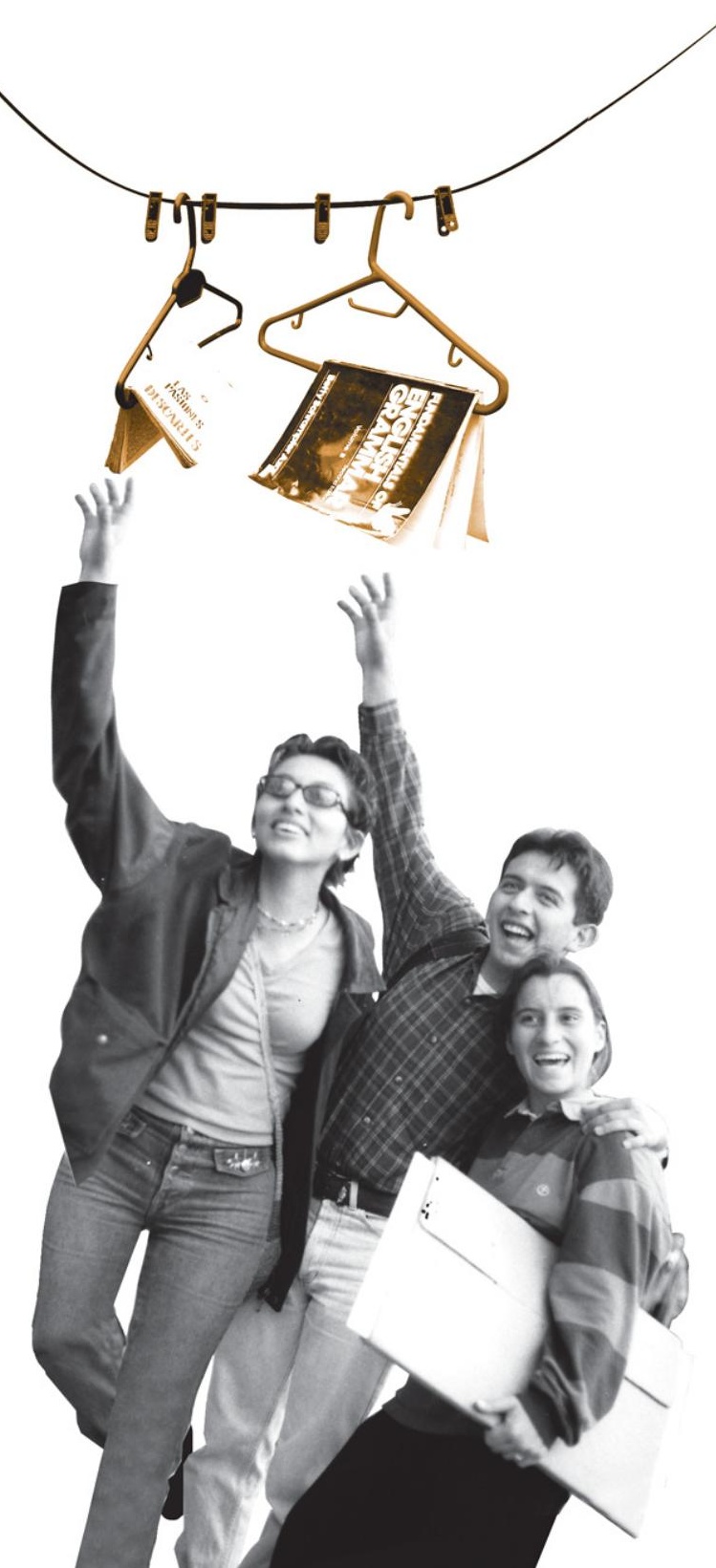

las dinámicas de formación que implicaran estudiantes. Concebido con la singularidad de que el Centro de Memoria no sólo guardara archivos específicos, sino de que a la vez tuviera prerrogativas organizacionales de actuación en prácticas pedagógicas de formación y organización de cursos para estudiantes, que se crearan líneas de publicación y divulgación de investigaciones, que se constituyera en un lugar para el desarrollo a partir de las investigaciones, fue la salida institucional y académica para que el CME no fuese sinónimo de archivo, y se configurara como un espacio privilegiado para el desarrollo de investigadores interesados en temáticas relacionadas con la memoria.

Sin embargo, sabiendo que los archivos pueden seducir, teníamos claro que el CME no debería ser reconocido como un lugar más de cuidado documental, sino por ofrecer una variedad de acciones que hicieran del Centro un órgano para la investigación. 


\section{Trampas}

No mundo há muitas armadilhas e o que é armadilha pode ser refúgio e o que é refugio pode ser armadilha

\section{Ferreira Gullar,}

Dentro da noite veloz

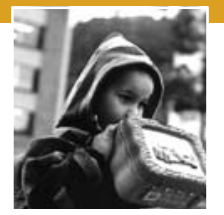

Como siempre ocurre, aquellos que están movidos por la pasión y actúan bajo el efecto de la seducción, están en disposición para encontrar el siniestro, por ello hacemos un esfuerzo para percibir nuevamente la realidad. Estudios sobre memoria, historia, cultura y patrimonio realizados con mirada curiosa, favorecen reflexiones sobre las trampas que el proyecto puede contener.

La revitalización de la memoria como tema y como referencia para estudios culturales, artísticos e históricos, como sinónimo de patrimonio y como atributo de la cognición, debe ser entendida en sus singularidades. Memoria es hoy una instancia para luchar por los derechos civiles, ya que es constitutiva de la ciudadanía y es valorada en la formación de las identidades culturales de diferentes grupos sociales. En esta revitalización del tema hay una positividad política explícita y, sin duda, un retorno a la poética, algunas veces romántica de la memoria como recuerdo, como actualización del pasado y como espectáculo que es, al mismo tiempo, la aceptación de las trazas del pasado en el presente y de la memoria como sinónimo de vida.

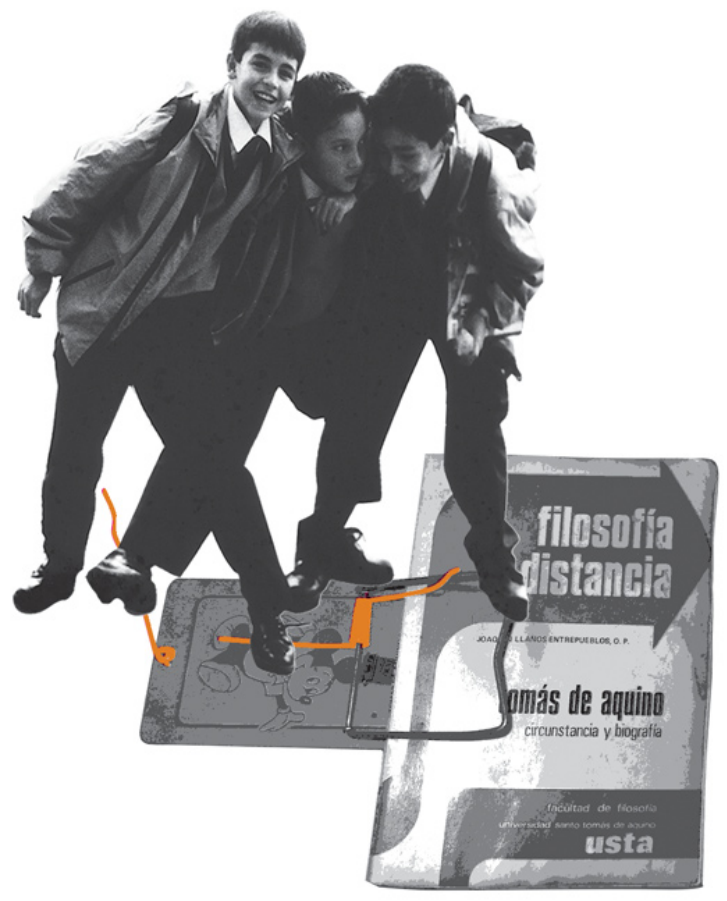

Como nos recuerda Seixas (2001), al referirse a los estudios de Pierre Norá, la memoria es la tradición vivida, 'memoria es vida', es la actualización en el 'eterno presente', es espontánea y afectiva, múltiple y vulnerable. Para Norá, así como para Marrou, la historia es diferente de la memoria, justamente por la operación crítica que el historiador hace al construir un discurso historiográfico. Sabemos, por Halbwachs, que la memoria histórica es un producto artificial, con un lenguaje prosaico y enseñable (Catroga: 2001).

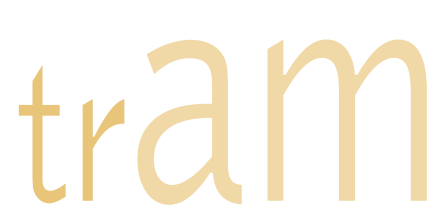


Como elemento constituyente de la identidad y por otorgar al ser humano capacidad de reconocimieto entre los suyos, la memoria es valorada como resistencia al olvido y a los silencios que nos son impuestos en épocas de vulnerabilidad, cambios y excesos de información o destrucción (Colombo: 1991).

En el campo de la educación, las discusiones sobre memoria tienen significado al retomar el 'lugar del sujeto', ya que ésta, concebida como capacidad cognitiva (memoria / conocimiento) o como función política (memoria voluntaria y memoria colectiva), permite repensar a los sujetos directamente implicados en procesos educativos, por prácticas de intervención, acción institucional y reglamentada a través de dispositivos de regulación social. Es el 'lugar de la memoria del sujeto' contado, vivido o imaginado, ya que la virtualidad es una de las características de la memoria.

Ahora bien, construir espacios y lugares que 'abriguen', guarden y protejan vestigios del tiempo para promover recuerdos (como ocurre en la proliferación de los museos) o para ser examinados por las atentas miradas de los historiadores (en archivos y centros de documentación), genera un incontenible efecto seductor: nos asegura como intelectuales defensores del patrimonio cultural, al tiempo que nos permite mostrar preocupación por la educación de las futuras generaciones.

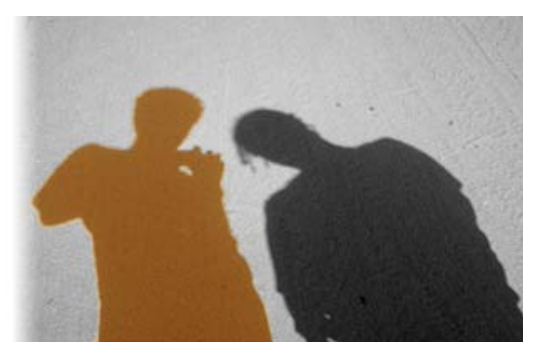

Pero como dice el epígrafe, algunas veces el refugio puede ser la trampa. Colombo (1991) nos llama la atención sobre el hecho que vivimos una obsesión por la memoria en la construcción de archivos, y Huyssen (2000) destaca que vivimos, paradójicamente, seducidos por la memoria. De un lado, la obsesión por la memoria y por el pasado, como intento de mantener encendida la recordación de los traumas, y el esfuerzo para que la alteridad sea constituyente de las relaciones sociales en mundos masificados. Es la anamnesia como cultura. De otro lado, se acusa a la cultura contemporánea de amnésica, de embotamiento y apatía, porque la información nos absorbe y entramos en el consumo de la información y de los productos, de forma que todo se torna obsoleto instantáneamente, dejándonos cada vez más a merced de los olvidos provocados por la ausencia de vínculos con los objetos, la producción, la información ${ }^{3}$.

4 Huyssen (2000) destaca que la sociedad informatizada utiliza los computadores como un recurso seguro y de larga duración, pero los computadores tienen menos de 50 anos de existencia y ya he ha hecho necesario crear una arqueología para la lectura de programas y de estructuras de almacenamiento de información, justamente por la enorme contradicción entre producción y consumo presentes en esta herramienta. 
La trampa de valorar la memoria por el rico pasado que contiene, así como por el futuro que representa, nos pone frente a la 'monumentalización' y 'fetichización' de la memoria y, claro, de los espacios, lugares o cosas que promuevan rápidamente esa operación de defensa de la memoria en los sujetos.

Por otro lado, sabemos que memoria y olvido son partes de un mismo proceso. Freud enseñó que la memoria y el olvido están indisoluble y mutuamente ligados; que la memoria es apenas otra forma de olvido y que el olvido es una forma de memoria escondida. Pero que Freud describa como los procesos psíquicos de la recordación, que recalcan y olvidan en un individuo, vale también para las sociedades de consumo contemporáneas, como un fenómeno público de proporciones sin precedentes que puede ser históricamente interpretado (Huyssen, 2000, 18)

En esa sociedad de valoración / desvaloración de la memoria, los archivos, las bibliotecas y los museos ocupan un lugar destacado porque, por medio de ellos, es posible promover acciones educativas que puedan repercutir y reproducir la cultura de la anamnesia / amnesia. Pensado en crear un espacio especializado en memoria como este, en una Facultad

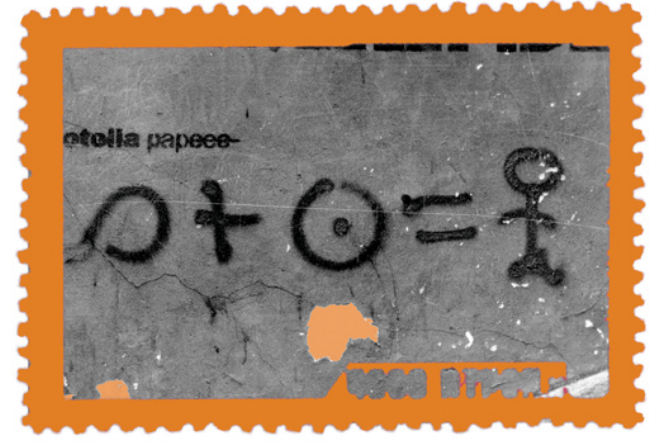

de Educación, cuya marca académica es observar críticamente la educación como proceso de producción y reproducción de la cultura, tenemos un dilema que puede ser transformado en una trampa, porque algunas veces nos sentimos desanimados o excesivamente críticos en nuestra acción. 


\section{Olvido}

É preciso não esquecer nada: nem a torneira aberta nem o fogo aceso,nem o sorriso para os infelizes nem a oração de cada instante.

É preciso não esquecer de ver a nova borboletanem o céu de sempre.

O que é preciso esquecer é o nosso rosto,o nosso nome, o som da nossa voz, o ritmo do nosso pulso.

O que é preciso esquecer é o dia carregado de atos, a idéia de recompensa e de glória.

Cecília Meireles,

É preciso não esquecer nada

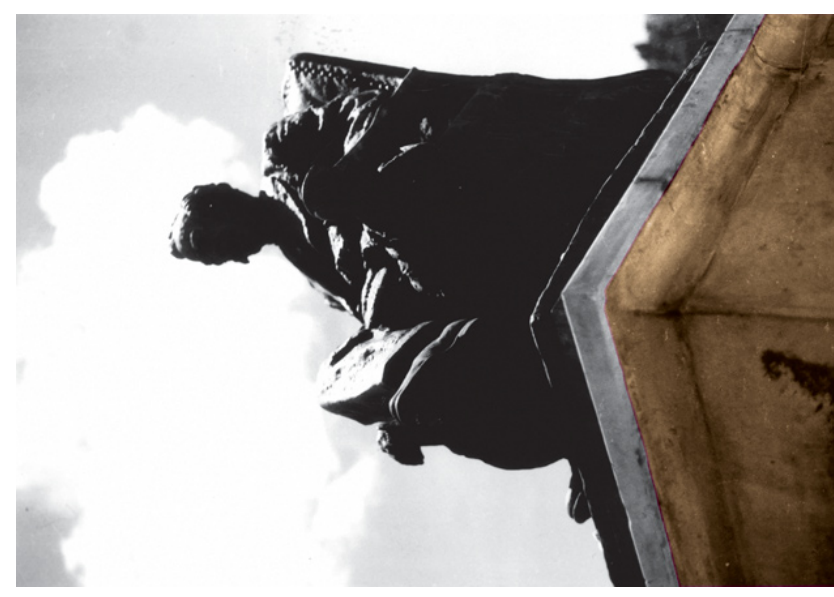

La idea de que memoria y olvido son indisociables, tiene solucionada parte de las cuestiones conflictivas con las escuelas de la memoria. Ferreira (2004), al analizar el olvido existente en las narrativas, advierte que la dupla olvido / memoria está en aparente oposición porque, indisociadas, dan cuenta de ejes de conflicto, una vez que individuos y grupos echan mano de la selectividad y de la expulsión de los elementos indeseables en momentos de tensión.

Pierre Norà (1997) afirma, sobre el 'lugar de las memorias', que es condición fundamental para el historiador el cuestionamiento constante, la superación de que las prácticas no son positivas, pero tampoco liberales ni románticas, que persisten aún hoy en espacios culturales que han cristalizado como depositarios de una memoria única, exclusiva, jerarquizada, descontextualizada, despolitizada e hiperrealista. Para él, la memoria es la tradición vivida: 'memoria es vida', es la actualización en el 'eterno presente', es espontánea y afectiva, múltiple y vulnerable. La historia, al contrario, es una reconstrucción intelectual, una representación sistemática y crítica del pasado (Seixas: 2001). 


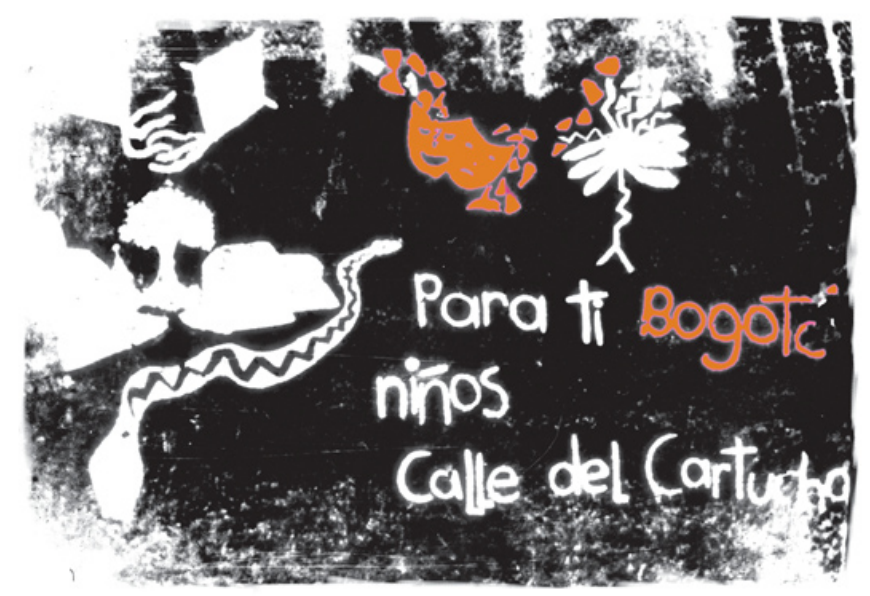

(Seixas: 2001), recuerda que las discusiones contemporáneas sobre memoria, como lo hacen Bergson y Hanna Arendt, buscan comprender la complejidad alcanzada con la capacidad humana de lidiar simultáneamente con el recuerdo y el olvido; con las funciones prospectivas y proyectivas, con los tiempos: pasado y futuro, en el presente. La reiteración de una memoria capaz de vincular la identidad individual y colectiva, en una sociedad en que esas identidades son factores de diferenciación, pero también de sumisión, de jerarquización y de deslegitimación social de grupos e individuos, presenta el paradigma de la memoria como esencial en las relaciones políticas que rodean esos sujetos.

La defensa del derecho a la memoria en tiempos actuales, no trata solo de las memorias como recuerdos románicos y del confort del pasado, se refiere también a la necesidad de seleccionar del pasado elementos que fortalezcan a los sujetos. Ese juego de recuerdos y olvidos, como nos recuerda siempre Seixas, adquiere importancia capital en esta época de ausencia de las utopías históricas porque apuntan a su realización.

La memoria es transitoria, notoriamente no confiable y susceptible de olvido; en suma, es humana y social. Dado que la memoria pública está sujeta a cambios (políticos, generacionales e individuales) ,no puede ser almacenada para siempre ni protegida en monumentos; tampoco, en este particular, podemos nosotros confiar en sistemas de rastreo digital

para garantizar coherencia y continuidad. $\mathrm{Si}$ el sentido del tiempo vivido está siendo renegociado en nuestras culturas de memoria contemporáneas, no debemos olvidar que el tiempo no es apenas el pasado, su preservación y transmisión. Si nosotros estamos, de hecho, sufriendo un exceso de memoria, debemos hacer un esfuerzo para distinguir los pasados usables y los prescindibles (...). Lo mismo que la amnesia sea un producto del ciberespacio, precisamos no permitir que el miedo y el olvido nos dominen. Allí, entonces, tal vez sea hora de recordar el futuro, en vez de apenas preocuparnos del futuro de la memoria (Huyssen: 2000)

En este sentido, la articulación entre la memoria y la educación es más que una tarea de reconocimiento del pasado. A la educación y los estudios sobre la memoria subyacen preocupaciones sobre el futuro. En el caso de este trabajo nos referimos al futuro que habita en la memoria. 

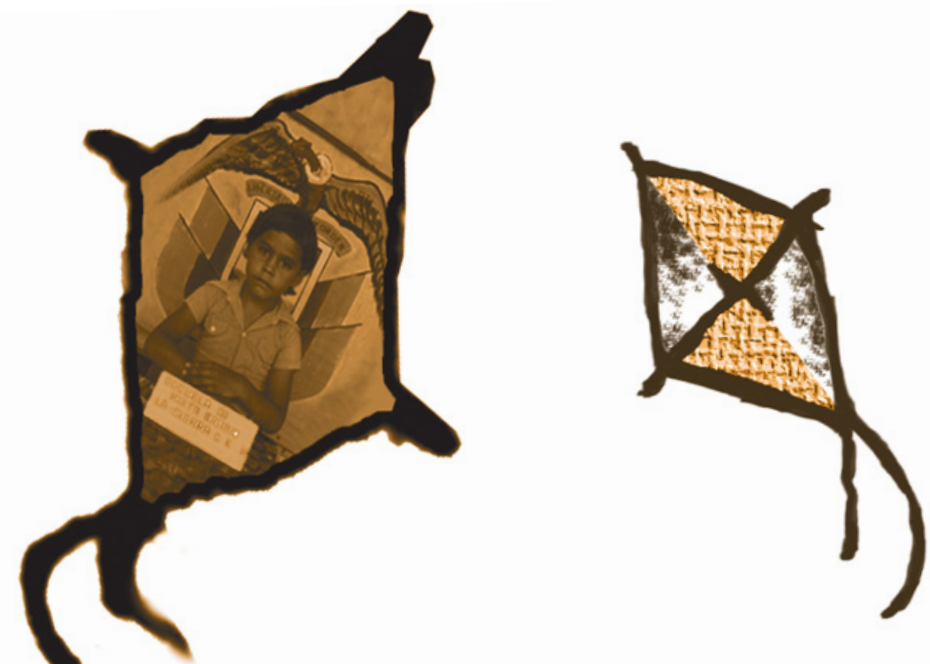

En este sentido, un Centro de Memoria de la Educación en una 'era de información y tecnología', tiene un papel significativo por cumplir, pero es importante no olvidar, como dice el epígrafe, las cosas esenciales. Es preciso relativizar el papel social de estos lugares, ver su transitoriedad y comprender que la acción de cualquiera de estos centros corresponde a un proyecto del tiempo presente. Al hacer accesibles innumerables datos, fuentes y fondos documentales a un número más amplio de investigadores, el CME puede constituirse en un foro público de investigación, capaz de fortalecer la dimensión del sujeto histórico, concebido como productor de reflexiones, de conocimientos históricos y fabricante de memorias. Su papel significativo también es de subsidiar el trabajo intelectual y preservar la transparencia de las formas de producción de los conocimientos y del propio documento, pero debemos tener en mente su transitoriedad.
Estas cuestiones revelan un dilema que a los archivistas puede parecer extemporáneo (cuestiona la esencia del pasado contenido en el documento), por cuanto se muestran las dudas que surgen sobre la selectividad de los saberes y el poder del cual se hayan investidos.

La creación del CME, además de estar atenta a las necesidades imperiosas de crear condiciones para un amplio desenvolvimiento de las investigaciones y la formación en humanidades, de cumplir con el compromiso de salvaguardar fuentes para que tales investigaciones sean realizadas, nos traza también, y simultáneamente, la necesidad de pensar, como recuerda Martín-Barbero (2000), el discurso de la memoria que se realiza desde el poder, aquel que busca la creación de un sujeto homogéneo y que se libera en la retórica de la creación de una narrativa total, de los excluidos y de los 'diferentes'. 


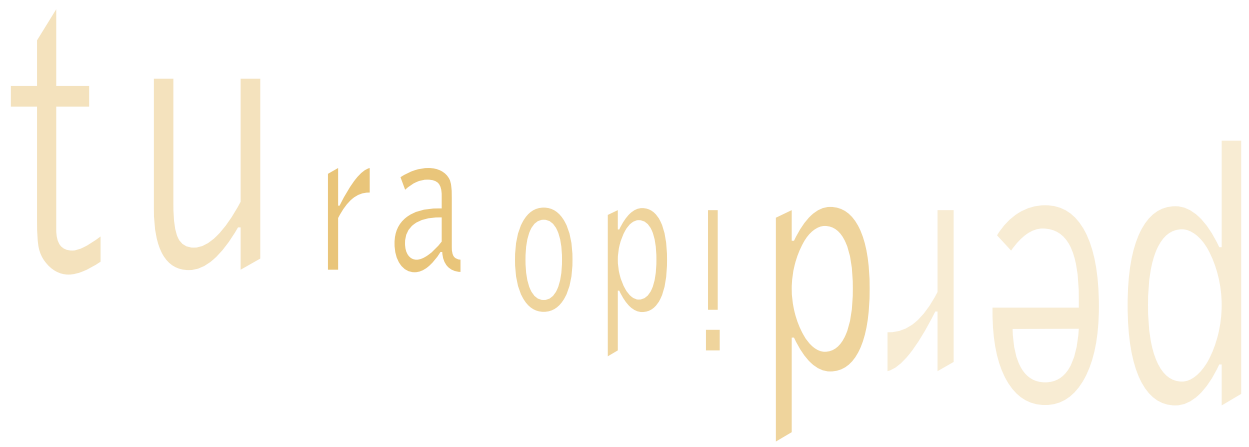

Podemos incurrir en el mismo peligro si identificamos al Centro como un espacio privilegiado de un saber total, 'senor de la memoria y del olvido' (Le Goff: 1997), si promovemos acciones de 'empoderamiento' de este lugar como aquel que puede contener la verdad, el 'lugar de la memoria'. Además, hay que considerar que en esta época de información acentuada, conseguimos hacer muchos ejercicios protectivos, pero casi no logramos construir proyectos colectivos. El exceso de datos y de informaciones crea el simulacro de que tenemos un conjunto de saberes que, por sí solo, u ordenados de manera frívola, permiten hacer proyecciones sobre el futuro. Con esto queremos reiterar que las seducciones y las trampas están, todo el tiempo, muy cerca de nosotros.

Resta un último aspecto para reflexionar en este artículo, que busca articular de manera coherente investigación y práctica cultural, sin pretender eliminar las contradicciones que persisten en todas las situaciones reales. Se trata de lo incómodo.

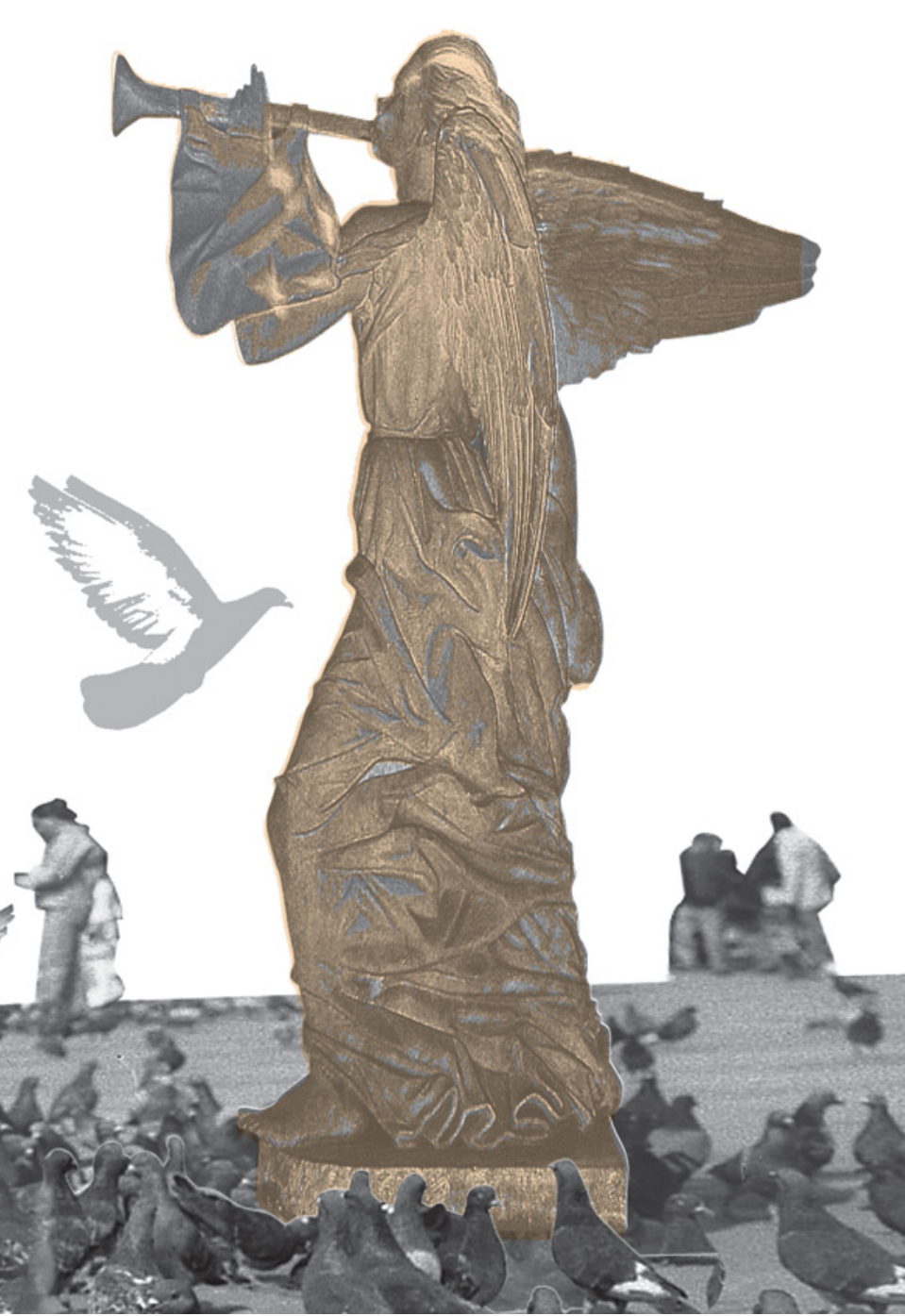




\section{Incómodo}

\section{Este é tempo de partido,}

tempo de homens partidos

Em vão percorremos volumes,

viajamos e nos colorimos.

A hora pressentida esmigalha-se em pós

na rua.

Os homens pedem carne. Fogo. Sapatos.

As leis não bastam. Os lírios não nascem

da lei. Meu nome é tumulto, e escreve-se

na pedra.

Carlos Drummond

de Andrade,

Nosso Tempo

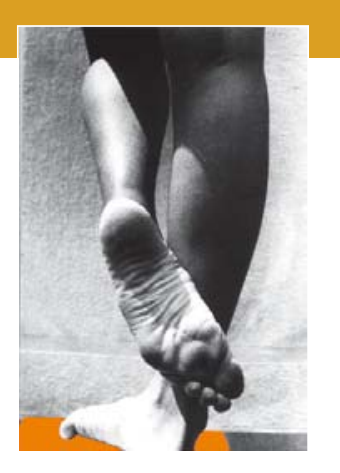

Lo más incómodo de la construcción del CME, hasta este momento, ha sido la tentativa de fijarlo como creación colectiva. El CME sólo puede ampliar sus acciones en la medida en que pueda establecer alianzas con otras instituciones similares y afines, evitando así la duplicidad y la competición entre ellas. Pero en época de tanta fragilidad en la creación de relaciones públicas en los ámbitos universitarios y otros espacios institucionales, promover esas articulaciones no es tarea fácil, sobre todo cuando se trata de la organización de colecciones, de fuentes o de la disputa por la financiación de investigaciones.

Además de esto, la gestión colegiada del CME todavía no está plenamente definida. Hay que pensar cómo convertir el Centro en un espacio para diferentes propuestas de trabajo e investigación. En una paradójica cultura de amnesia/ anamnesia, de todos lados aparecen solicitudes para que el CME reciba documentos para su preservación. Los pedidos son muchos, desde grupos de investigación de la Facultad de Educación, que por diferentes motivos coleccionaron materiales, hasta escuelas que quieren que hagamos una especie de apología de la institución. Algunas veces, el Centro es entendido como un prestador de servicios generales en cuestiones de memoria. La gestión de la información especializada es $-y$ todo parece indicar que así será por un largo tiempo-, una cuestión importante en la implantación efectiva del CME. Preguntas sobre ética y política, en las disputas relativas a la memoria y a la producción de saber académico y científico, acompañan de manera permanente la construcción de este proyecto, no sólo como señalizadores de actitudes a ser asumidas, sino en función de la propia lógica de producción del conocimiento en el cual estamos insertos y que precisa ser observada críticamente.

Pero la memoria incómoda viene acompañada de ideas sobre identificación y proyección. Con la comprensión de la noción de memoria incómoda podemos construir entendi- 
miento sobre la opresión, la legitimidad social (y la ausencia de ella) de los sujetos, sobre la dialéctica de identificación del oprimido con su opresor y sobre la simbiosis entre dominación y resistencia. Memoria y poder están intrínsecamente asociadas a las cuestiones de identidad de los grupos sociales. Reconocer eso en una sociedad democrática es reconocer también el derecho a las diferentes memorias. Estudios sobre las culturas populares y sobre movimientos sociales, por ejemplo, valoran, más que nunca, retomar las cuestiones de la memoria. Se percibe también una ampliación de las políticas, locales o nacionales para retomar acciones que valoren la memoria y la historia local, pisoteadas en la creación de 'lugares' para exposición de colecciones que dejan a la vista y con fácil accesibilidad, elementos simbólicos de esas memorias.

Curiosamente, en la historia del Brasil Republicano, los periodos en que las cuestiones de la memoria ganaron mayor incentivo,

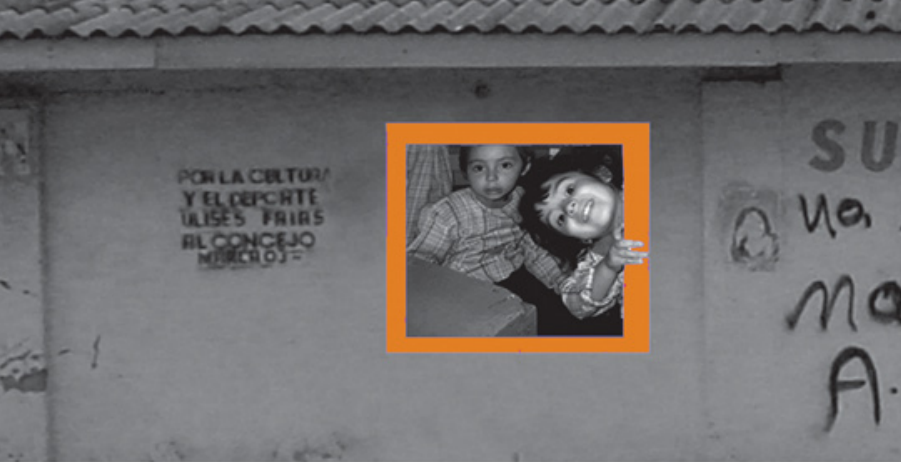

desde el punto de vista de las acciones culturales, por medio de políticas públicas, fueron especialmente durante las dictaduras de Vargas (1937 - 1945) y de los militares (1964 - 1985). En estos dos periodos, las discusiones sobre lo nacional y lo regional ganaron importancia, especialmente desde el punto de vista político, en una enfática tentativa, por parte de los grupos dirigentes, de construir un proyecto nacional de desarrollo (Ferreira y Delgado: 2003; Soares y D'Araujo: 1994). Conocer lo regional y transformarlo en componente constituyente de la cultura nacional, aseguró no sólo una sociología realizada a partir del Estado, también un amplio control sobre los grupos sociales, que ganaron mayor visibilidad y fueron incentivados a reflexionar sobre sus propias condiciones de reproducción cultural, sobre sus tradiciones y, evidentemente, establecieron acciones para el descarte de los elementos culturales que se mostraran contradictorios o conflictivos con el proyecto mayor.

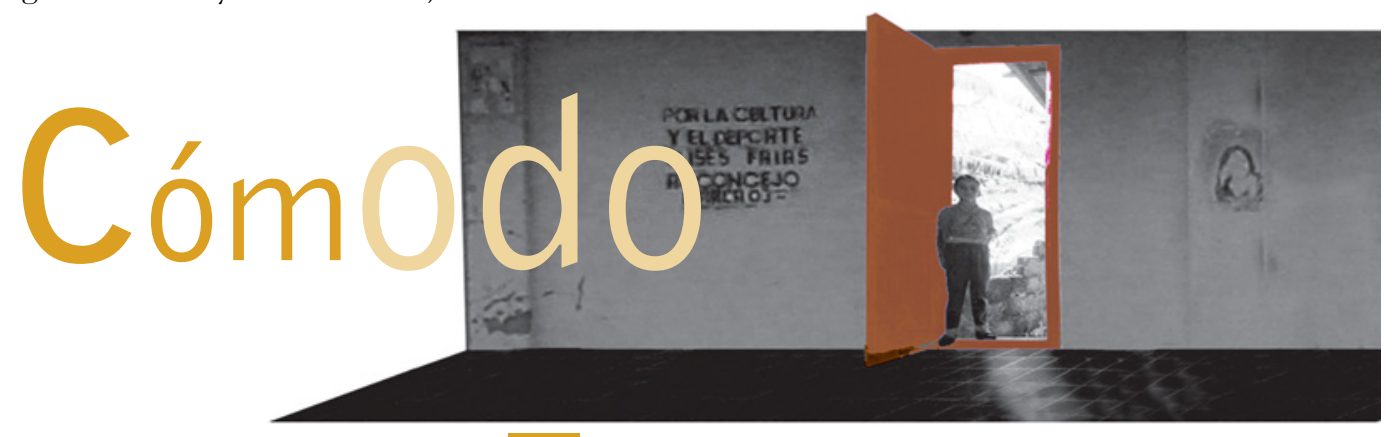


Esta acción interventora, de control sobre la cultura de los grupos sociales, tuvo la marca de la construcción de memorias y de la identificación de lugares para la memoria colectiva, institucionalizados. Proyectos de museos pedagógicos de la era de Vargas, legislación sobre Patrimonio histórico, definición del papel de la universidad como principal responsable por la salvaguarda de determinados documentos, fijado desde el nivel federal, durante el periodo de la dictadura militar, demuestran la necesidad de estar atentos a los componentes ideológicos de nuestras frágiles instituciones públicas y también a la construcción de nuestra democracia y nuestros espacios públicos.

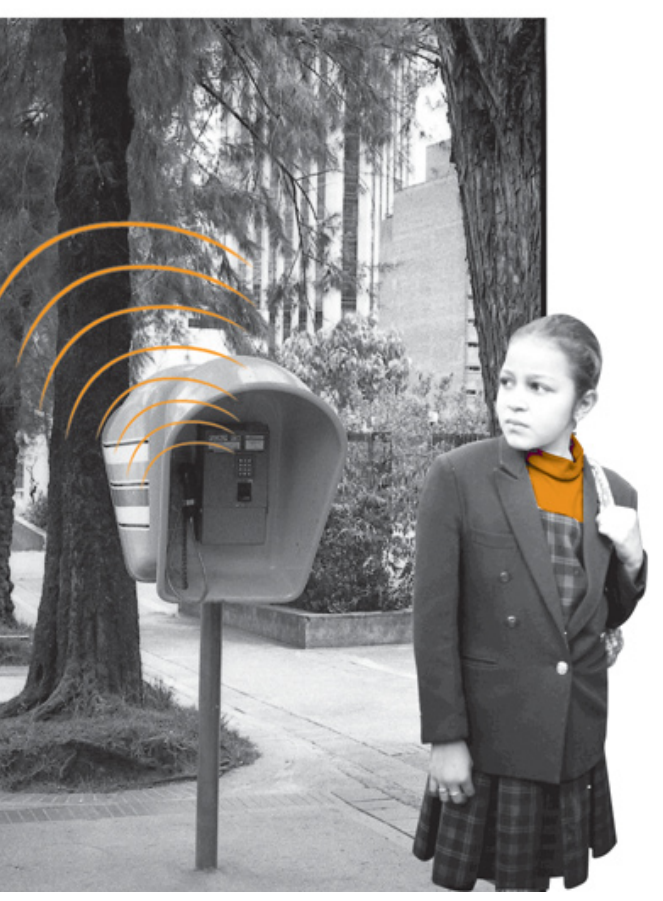

Dicho esto, volvamos a la preocupación con la 'memoria incómoda', porque, como ya dije, se refiere, en cierta medida, a la identificación del opresor y del oprimido. La educación escolar, y toda su hiper-representación en las comunidades nacionales, ha sido bastante valorada como un bien y un derecho social, al mismo tiempo que se la presenta como un deber del Estado y un derecho del individuo. Al enfatizar investigaciones sobre memoria de la educación, hay que prestar cuidado especial para evitar que, en la búsqueda de documentos y fuentes, los y las valoremos demasiado, dejando de lado una cuestión fundamental para la memoria, que es la percepción de los conocimientos subyugados, tanto en los espacios formales de educación, como en los espacios no formales en los cuales, las fuentes apenas son susceptibles de reconocimiento y recogimiento para su sistematización.

Al trabajar con la memoria incómoda, procuramos estar atentos a los sujetos, en su vida cotidiana y en su tiempo presente, lo que implica distintas concepciones de conocimiento, que se cruzan con tradiciones y manifestaciones culturales que algunas veces resultan contradictorias y conflictivas. Nosotros, al reconocer la existencia de visiones alternativas y democráticas, en una sociedad de educación y cognición, valoramos en demasía conocimientos que ocupan u ocuparon espacios inferiores en esa sociedad. El contacto con esa subyugación y con el borramiento de sus rastros, nos lleva a reflexionar sobre el papel social de profesores, intelectuales, gestores y políticos vinculados a la educación, educadores laicos, etc. ${ }^{4}$. En el proceso de reflexión crítica, la memoria incómoda entra en acción, permitiendo la reflexión sobre las experiencias, las vivencias, posconflictos y las confrontaciones de su propia construcción memorial y biográfica.

\footnotetext{
4 La preocupación con la manera como los profesores comprenden su propia actuación profesional, como y porque ingresaron y permanecieron en el magisterio han ayudado a comprender mejor las resistencias, las tradiciones, los cambios que ocurren en la enseñanza en la relación con los alumnos, en procesos de auto reflexión. Sobre esto ver Goodson (1995) y Martins (2004 e 2005).
} 
La memoria incómoda aquí es abordada como aquella que, expuesta y percibida, ayuda a los sujetos a tener conciencia de cómo sus visiones del mundo son construidas. La confrontación con las memorias incómodas puede alterar la percepción de las fuerzas que las definen y posibilitan alteraciones, también, en sus perspectivas y actuaciones. Ponemos nuestras expectativas en que el Centro de Memoria de la Facultad de educación UNICAMP sea movido mucho más por lo incómodo que por la seducción de la memoria como patrimonio, aunque estas separaciones no sean tan marcadas. $₫ \mathrm{e}$ y $\mathbf{c} \square$
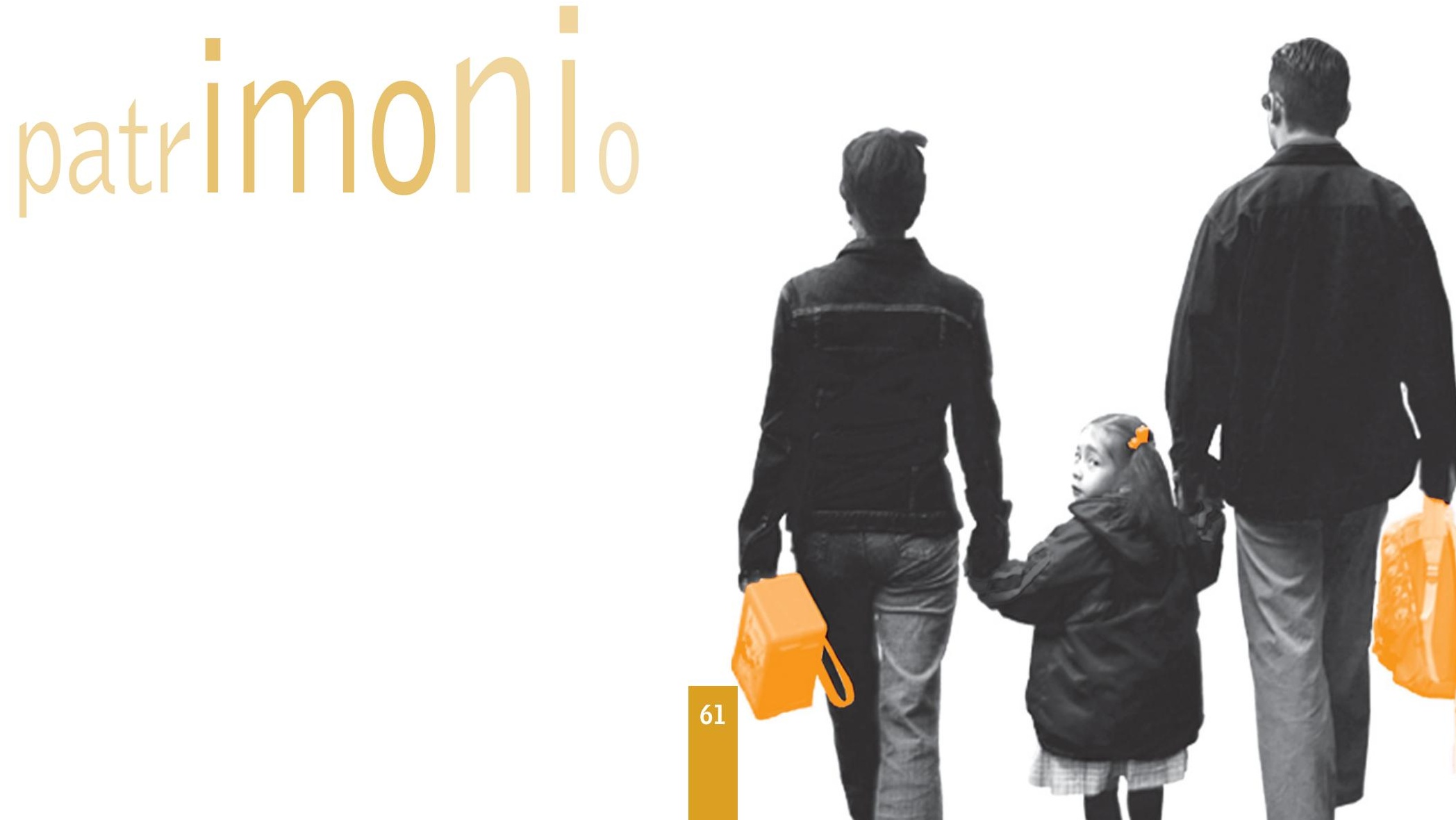
Le Goff. J. História e memória. Campinas: Editora da Unicamp, 1997.

Martín-Barbero, Jesús. El futuro que habita la memoria, en: Gómez, G. S. Y Obregón, M. E. W. (comps) Museo, memória y nación. Ministerio de Cultura/Museo Nacional de Colombia: Bogotá: 2000.

Martins, Maria do Carmo. Os desafios para a organização do Centro de Memória da Educação da FE/UNICAMP - ou de como construir coletivamente um "lugar de memória”. Unicamp, 2004.

www.fe.unicamp.br/servicos/centro_memoria/pesquisa/evora.pdf.

Martins. M. C. "E se o outro é o professor? Reflexões acerca do currículo e histórias de vida", en: Gallo, S. e Souza, R. M. Educação do Preconceito: ensaios sobre poder e resistência. Campinas: Alínea, 2004.

Martins, M. C. ““Eu me lembro que escolhi...”: memória e poder na seleção dos conteúdos para o ensino - abordagens no campo curricular", en: Corbalan, A. (org) Enredados por la educación, cultura y política. Buenos Aires: Biblos, 2005.

Menenses Ulpiano, T. Bezerra de. "A crise da Memória, História e Documento: reflexões para um tempo de transformações", en: Zélia Lopes da (org) Arquivos, Patrimônio e Memória - Trajetórias e Perspectivas. SP: Ed. UNESP/FAPESP, 1999.

Norá, Pierre. Le lieux de memoire: la republique. Paris: Gallimard, 1997.

Seixas, Jacy Alves de. "Percursos de memória em terras de história: problemáticas atuais", en: Bresciani, Stella e Naxara, Márcia (orgs) Memória e (res)sentimento indagações sobre uma questão sensivel. Campinas: Unicamp, 2001.

Soares, G. A D.; D’Araújo, C. 21 anos de regime militar - balanços e perspectivas. Rio de Janeiro: Editora da Fundação Getúlio Vargas, 1994.

Menenses Ulpiano, T. Bezerra de. "A crise da Memória, História e Documento: reflexões para um tempo de transformações", en: Zélia Lopes da (org) Arquivos, Patrimônio e Memória - Trajetórias e Perspectivas. SP: Ed. UNESP/FAPESP, 1999.

Norá, Pierre. Le lieux de memoire: la republique. Paris: Gallimard, 1997.

Seixas, Jacy Alves de. "Percursos de memória em terras de história: problemáticas atuais", en: Bresciani, Stella e Naxara, Márcia (orgs) Memória e (res)sentimento indagações sobre uma questão sensivel. Campinas: Unicamp, 2001.

Soares, G. A D.; D’Araújo, C. 21 anos de regime militar - balanços e perspectivas. Rio de Janeiro: Editora da Fundação Getúlio Vargas, 1994. 
e ducación y c i u d a d / 10

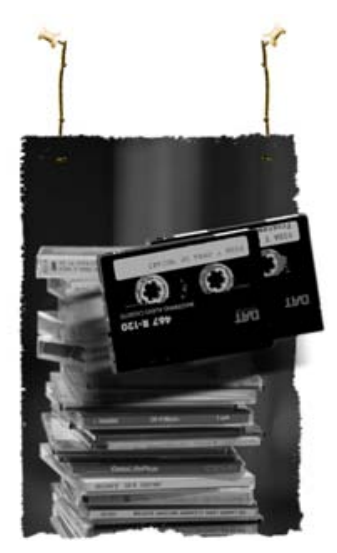

64 